\title{
The inspirational role of Chomsky in the cognitive turn of psychology
}

\author{
Csaba Pléh \\ Central European University, Budapest; \\ Collegium de Lyon \\ vispleh@ceu.edu
}

\begin{abstract}
The paper reviews the role of Noam Chomsky in the conceptual changes in modern psychology that are described by many as the cognitive revolution. Several aspects of the work of Chomsky are identified as key elements in the changes regarding the human mind, and the determinants of human nature. The mentalism of Chomsky resulted in the general spread of theory theories about human development, where the human mind is interpreted as a theory-using open, creative system. The peculiarities of sequential behavioral organization and later the sequential interface issues as well as the concentration on (syntactic) pure form were important inspirations for several general theories of human cognition. Chomsky, with his differentiation between competence and performance, opened the road along with David Marr to multilayered computational theories of the mind. While the innatist commitments of Chomsky regarding human development created many fruitful controversies during half a century, they also tied the underdetermined nature of human language with the philosophical issues of freedom. Language with its innate recursive system is a basic factor of human freedom. Freedom is connected to a rational image of humanity.
\end{abstract}

Keywords: Noam Chomsky; mentalism; theory theories; syntactic theories of mind; innatism; freedom and language

This is a mainly historical paper. I do not intend to analyze the validity or veracity of the linguistic theories of Chomsky, and their precise role in the development of modern psycholinguistics. My modest aim is to show the historical role of his theories in the shaping of modern cognitive science. The paper mainly concentrates on the outline of these influences, and rarely goes into the details of the impact.

The mid-20th century certainly was characterized by dramatic changes in the outlook of experimental and theoretical psychology, and in general in the fields that have gradually become the cognitive sciences. For quite a while this change of outlook has been labelled (or self labelled) as a cognitive revolution, in several autobiographic accounts (Bruner 1983; 1997; Miller 2003) and in overviews such as Gardner's (1985) by now classic personalized treatment of these events (for more distanced interpretations, 
see Baars 1986; Greenwood 1999). Through a variety of different influences would-be cognitive psychologists came to realize two important aspects in mid-20th century. First, the human mind has a real existence. It is "real", in the sense that its effects are seen in behavior. Further, there are scientific ways to study the mind without losing the objectivity professed by behaviorism and the governing positivist philosophy. The mind can be brought to experimental studies using indirect measures, and its workings can also be modelled by computer programs. According to many participants the precondition for the cognitive revolution was a disappointment with behaviorism and a motivated rejection of behaviorism (Gardner 1985). There was a dramatic shift of interest and terminology in mainstream experimental psychology between the 1960s and 1980s. A new image was born where the basic determinant of behavior is not the stimulus itself but its interpretation, the internal model of the environment. There was a thematic shift and a desire to overcome behaviorism, which motivated the protagonists to speak of a new scientific paradigm as a cognitive revolution. The essential point of this novelty was the rediscovery of humans as knowers. A vision was gradually created according to which man can be seen as a being actively modeling the environment, and human behavior can only be understood with reference to these models (Pléh \& Gurova 2013). As shown by a later social history analyst (Cohen-Cole 2005), a most important aspect in this process was a postulated parallelism between the work of the scientist and the mental work of the individual ordinary knower. Both were interpreted as theory builders.

Many accounts consider the late fifties already as a crucial time for the changes. These were the times when the importance of Chomsky and modern linguistics in the changes within psychology first appeared (Baars 1986). George Miller, one of the founding fathers of the new movement, has designated a special moment for the birth date of the cognitive move. This moment would be a conference on September 11, 1956, the second day at a "symposium organized by the Special Interest Group in Information Theory at the Massachusetts Institute of Technology" (Miller 2003, 142). Here the new cognitive psychologists, such as Miller himself, the linguists represented by Chomsky, and the researchers of the new computer based approaches to thought represented by Newell et al. (1958) with their pattern searching problem-solving programs met. "In short, 1956 was a good year for those interested in theories of the mind, but it was only slightly better than the years just preceding and following. Many were riding the waves that began during World War II: those of servo theory, information theory, signal-detection theory, computer theory and computers themselves" (Miller 2003, 142). 
There certainly was and is an element of self-aggrandizement here, when the changes are referred to as a revolution, and several sober accounts do indicate that it was mainly a shift of emphasis from the behaving person towards the knowing person, rather than a real revolution (Mandler 2002a;b).

Within psychology, the new vision certainly created a group consciousness. In a sociological sense there certainly was a radical shift of emphasis, also supported in the 1970s by the new theories of the development of science and the concept of scientific paradigms and revolutions. The idea that science is theory-dependent was crucial for the new generation of cognitive psychologists. The message was simple. There are drastic changes in science, and we, the new cognitive forces, may be the agents of one of these drastic changes:

"[...] there clearly was a sociological shift in that psychologists appeared to
become persuaded that the cognitive research program was more promising
than the behavioral research program. This shift was not logically compelled
but rather was a function of $[\ldots]$ the persuasive writings of key cognitive
researchers and theorists (e.g., Chomsky). [...] unlike a bona fide scientific
revolution this shift in emphasis is best characterized as a sociological phe-
nomenon - a change in allegiance that interestingly may be due in part to the
claim (which has immense rhetorical value) that a scientific revolution has
indeed taken place."
(O'Donohue et al. 2003, 85)

It is worth remembering that the very notion of paradigm as applied by Kuhn $(1962 ; 1970)$ to comprehensive models and their shifts in natural sciences was treated in an ambiguous manner by the psychologists themselves. Some of them, like the dissident learning theorist/cognitivist Palermo (1971; Weimer \& Palermo 1973) proposed drastic shifts and a sequence of psychology of consciousness $\rightarrow$ behaviorism $\rightarrow$ cognitive psychology. Others, like Thomas Leahey (1987) realized the softer nature of psychology, talking about it even as a "multiparadigmatic science". This would imply a more social than conceptual change in the case of the cognitive paradigm shift as well.

From the trilogy of mind, cognition, affection, conation (see Hilgard 1980 about this heritage) they cultivated almost exclusively cognition. In classical cognitive research we arrive at a rather peculiar view of human life. We have a thoughtful contemplative man who concentrates on the form of representations. They started to treat not merely science but also the individual knower as "theory dependent", as a being characterized by strong internal theories. As shown by a later social history analyst (CohenCole, 2005), a most important aspect in this process was a postulated thoroughgoing parallelism between the work of the scientist and the mental 
work of the individual ordinary knower. Both were interpreted as theory builders. In these later changes, generative grammar and the associated philosophy of the mind had a crucial role.

As for linguistics, Chomsky himself in Olson et al. (1991) denies the use of paradigm shift for these changes, but both in his attitude and in the work of the first generation of Chomskyans there was an element of radical change in their criticism of previous models and the articulation of the novelty of their own model (Postal 1964; Katz \& Postal 1964).

The modern linguistics initiated by Chomsky promoted several inspiring ideas, which we can identify as Chomskyan input towards a general theory of cognition.

\section{Mentalism}

2. Theory theories

3. The centrality of form: the idea of syntactic pure form

4. The centrality of sequential thought

5. A computational theory of mind

6. Generic and specific innatism

7. Human freedom and the freedom entailed in human language

\section{The issue of mentalism}

The first important message psychologists have taken up from Chomsky was the idea that the human mind has a rich internal structure, in which language plays a central role. From the time of the cognitive revolution on, the mind ceased to be an empty abstraction in psychology, and language on its part also ceased to be an external appendage to an otherwise less structured human mind (Miller 1990). Chomsky was a key person in the general and strong appeal of linguistics attracting a new generation of psychologists in the 1960s. Roger Brown, one of the leading first-generation psycholinguists, identified and spelled out this attraction of psychologists, who felt a new appeal of grammatical organization in the mind. "It has taken the psychologists a long time to realize that the linguist means something when he says: 'Language is a system'. Very simply he means that 
when someone knows a language he knows a set of rules [...] The most important thing psychology can get from linguistics is the reminder that human behavior includes the response that is novel but appropriate" (Brown 1958, X-XI). This quote shows the impact of the new grammar: combining ideas regarding rules and creativity. Chomsky himself spelled out several times that in an abstract way linguistics itself is part of psychology - not unlike the way Quine (1969), a Harvard analytic philosopher, would claim a decade later that epistemology should become a chapter of cognitive psychology. Linguistics is "a branch of cognitive psychology" (Chomsky 1968, 1). It is "That part of psychology that focuses its attention on one specific cognitive domain and one faculty of mind, the language faculty" (Chomsky 1980, 4). Chomsky showed this association between linguistics and psychology in a programmatic manner in Language and mind already in 1968:

"The study of language may very well, as was traditionally supposed, provide
a remarkably favorable perspective for the study of human mental processes.
The creative aspect of language use when investigated with care and respect
for the facts shows that current notions of habit and generalization as deter-
minants of behavior or knowledge are quite inadequate. The abstractness of
linguistic structure reinforces this conclusion and it suggests further that in
both perception and learning the mind plays an active role in determining the
character of the acquired knowledge. The empirical study of linguistic univer-
sals has led to the formulation of highly restrictive and I believe quite plausible
hypotheses [...] that contribute to the attempt to develop a theory of acquisi-
tion of knowledge that gives due place to intrinsic mental activity. It seems to
me, then, that the study of language should occupy a central place in general
psychology."
(Chomsky 1968, 84)

Regarding the internal history of linguistic epistemology, the idea of a psychological reality of grammar had a methodological role as well. The early Chomsky followers started form an idealized image of deciding which grammar was better for a given language. In this decision process they started to believe in the superiority of the grammatical solutions that were assumed to have psychological reality.

Chomsky had an almost apodictically easy wording: psychology subsumes linguistics. His early mentalism also leads to another methodical claim: the belief that humans have access to the intricacies of their mental grammar through linguistic intuitions (Chomsky 1965). Later, however, he skipped this commitment to intuition, and started to claim that linguistic competence is an unconscious knowledge of language. As he said in an interview, "We don't have, we couldn't have, conscious knowledge of these principles" (Cohen 2004, 53). 
In the interpretation of his early philosopher follower, Jerrold Katz, mentalism also implies a causal role of mental events and grammar in language behavior: "linguistic theories must contain concepts which enable linguists to formulate the principles of mental operation that underlie speech" (Katz 1964, 126).

Chomsky's own statements on the mental reality of grammar motivated much work in the empirical study of the psychology of language, and also much theoretical discussion as well. The theoretical issues are mainly concerned with two problems. Do psychological studies give support for given particular linguistic solutions, and are they dealing with our basic competencies of understanding and production of sentences, or with some kind of metatheory about our abilities to judge our own sentences? Most importantly, however, the specific notions Chomsky introduced had a great effect on empirical psychology. Cognitive psychologists were not satisfied with the abstract identification of linguistics as a chapter of psychology, but looked towards developing a specific chapter of cognitive psychology, developing a modern-linguistics educated psycholinguistics. The Chomskyan inspiration showed up in two domains in the formation of this later central chapter of cognitive science: the experimental study of sentence understanding and later production in humans, and empirical, both observational and experimental studies on the unfolding of the linguistic system in children.

Language and psycholinguistics have played a central self-defining role for many cognitivists for over two generations by now. For an early summary two generations ago the little book of Judith Green (1973) is still a good historical source. Jacques Mehler (1969, 3), the Chomsky-trained French psycholinguist, when he analyzed the birth of the cognitive movement, underlined the changes in the philosophy of science associated with the cognitive movement, and the specific role of language sciences:

"During the last hundred years positivism was having an important effect; it is only since the last decade that it's felt less. As a matter of fact the decline of behaviorism seems to be related to the birth of modern psycholinguistics. The basic idea underlying the 'post-behaviorist' study of language in psychology was mentalism. It involved the basic assumptions of mentalistic linguistics that each speaker carries in her head a grammar of her language and this grammar is used in creating and understanding an infinite number of possible sentences, and second that speakers have an 'access' to this hidden language of theirs in forms of linguistic intuitions."

Katz (1964) warned very early on that there is a methodical problem if mentalism implies a reliance on intuitions: 
"the linguist can no more look into the head of a fluent speaker than a physicist can directly observe photons or a biologist directly observe the evolutionary events that produced the human species. The linguist, like the physicist and biologist, can only achieve scientific understanding by constructing a model of the system which contains a hypothesis about the structure of the components of the system that are not observable."

(ibid., 128)

Gradually, even Chomsky (1980) has given up his original belief that grammar is accessible for lay persons in the form of linguistic intuitions. $\mathrm{He}$ claimed eventually: "Our perfect knowledge of the language spoken by us does not give us access to these principles; we cannot even hope to be able to define them 'internally' relying on introspection or reflection" (ibid., 231). The indirect study of the mental representation of language has become the proper domain of psycholinguistics, rather than the direct use of intuitions. The mentalistic inspiration towards psychology has become an ontological mentalism, combined with a methodological objectivism. This was true not merely of the Chomsky inspiration, but of the whole of cognitive psychology. Cognitivists do not go back to traditional mentalim that was characterized by the use of introspection as the basic means of gaining psychological knowledge:

"The rise of cognitivism has not been, nor was it ever intended to be, a wholesale return to the mentalism of the past. [...] Instead, cognitivism was an answer to the problem: how can we introduce (at least part of) the mental back into scientific psychology while not falling prey to the criticisms that brought down the mentalism of old psychology and led us to behaviorism. In other words, how can we have our mental cake and eat it too? The answer that cognitivism has provided [...] is that as long as the aspects of the mental that are revived are restricted to those that are susceptible to truth-evaluation [...] then the behaviorists' criticisms of mentalism will be stayed."

(Green 1996, 37)

\section{Theory theories}

The general idea of a theory-based approach to humans, and especially to children, an interpretation of children as theory makers was outlined by Chomsky in several early trend-setting papers on innatism. The structure of the argument had implications and extensions for all of modern cognitive psychology. In this vision, language acquisition itself is a process of theory formation and hypothesis testing, and psychologically speaking, grammar itself is an implicit theory of the given language: 
"The [language acquisition] device might proceed to acquire knowledge of a language in the following way: the given schema for grammar specifies the class of possible hypotheses; the method of interpretation permits each hypothesis to be tested against the input data; the evaluation measure selects the highest valued grammar compatible with the data. Once a hypothesis - a particular grammar - is selected the learner knows the language defined by this grammar [...] his knowledge extends far beyond his experience and is not a 'generalization' from his experience in any significant sense of 'generalization'." (Chomsky 1967, 8)

The vision of the "child as a little linguist" was provocative and even seemed to be arrogant when it was first proposed. Chomsky promoted a conception of humans as individual carriers of a theory of their native language. This representation of language was assumed to be a theory in the strict sense held by the interpretation of Carnap (1934/1937) that was proposed for the language of science, also involving a separation of syntax and semantics in scientific language. This was certainly a strong antimetaphysical claim for a philosophical reduction of science as analyzed by Hintikka (1991). Still, the separation of form from content implied by this move has become a thorough impact of Chomsky on language processing research, and has become a central proposal for the entire modern cognitive psychology, alongside his proposal that humans are carriers of theories and they do develop specific theories in each domain of knowledge.

Skinner in 1963 criticized the vision of the child as being a little linguist by claiming that this was equivalent to the claim that if a dog is trained to do some balancing performance, one could as well suggest that the dog acquired an intuitive physics. At the time, this felt for the Skinner followers as a strong blow to the ontological generosity of the Chomskyans. But in reality, that is what happened in actual mentalistic cognitive research, and even in the case of many modern ethologists. The "theories in the mind" notion has evolved into a revolutionary general idea in late 20th-century developmental psychology. The theory notion has been extended beyond language to areas of physical and social knowledge. Humans started to be interpreted as carriers of physical and psychological naïve theories. This spread of theory theories has been a basic message of Chomsky in two respects regarding all human development. It embodied the idea of an innate organization as a starting point, and it suggested that all domains of knowledge are structurally organized. Today, we freely talk about naïve physics, naïve arithmetic and so on. The move started by infants being interpreted as little linguists continued by treating humans as entertaining theories of the mind and especially ideas about other minds (Leslie 1987), and theories about the articulation of the physical world (Spelke 2000). In an interesting manner, as shown by some of his new metatheoretical 
statements (Chomsky 2005; 2015; Chomsky \& McGilvray 2012) Chomsky himself was not happy when his innatism claims regarding language have become part of the biological inheritance talk. He reverted several times to the idea that language has innate constraints not due to a particular biological construction, but due to some universal laws of physics.

\section{The centrality of form: the idea of syntactic pure form}

In the famous examples of separating grammaticality and meaning with sentences like Colorless green ideas sleep furiously, Chomsky (1957) introduces the idea of the primacy of syntax and form into cognitive organization. As a consequence and analogy to this, the first generation of cognitive scientists interpreted humans as general-purpose symbol manipulating machines modeling human processes in flow charts and block schemata, with the central notion of representation. This was usually accompanied by a primary concentration on formal aspects both regarding representations and regarding the models of cognition. Cognitive research in the 1960s under the direct influence of Chomsky repeated for general cognition what had been initiated by linguistic and literary theories in the 1920s (early linguistic structuralism of the Russian formalists), and by the several waves of form-centered avant-garde artistic movements also in the 1920s.

The new experimental cognitive psychology of language in the 1960s had two new aspects that were directly related to Chomsky. It was dealing with sentences rather than words, and regarding sentences it treated syntactic form as a central component. This was parallel to the way syntax was being treated in formal linguistic theory as the central, novelty-generating component of grammar, with two types of interpretation around it, semantic and phonological interpretation. This was also extended into a general philosophical proposal of a syntactic theory of mind according to which all of our knowledge is organized in a sentence-like propositional manner (Fodor 1981).

This commitment to form had interesting technical consequences within psychology. Experimental cognitive psychologists have preserved the methodical commitments inherited from behaviorism. In designing their experiments, they clearly differentiated between independent and dependent variables. Stimulus preparation has become more and more sophisticated in modern cognitive psychology. In the new cognitive mode, the independent stimulus variables still had to be characterized in an independent manner, like the physical characterization of stimuli in classical experimental research. Now, however, linguistic and logical stimulus 
analysis entered the preparation of materials. As Roger Brown (1970, v) mentioned half a century ago, psychology journals have become filled with sentence trees and similar characterizations. With all changes in detail, this attitude remained a constant feature of the new psycholinguistics for half a century.

The entire idea of looking for the psychological reality of grammatical descriptions and rules was spelled out by Miller and Chomsky very early on:

"The psychological plausibility of a transformational model of the language user
would be strengthened, of course, if it could be shown that our performance
on tasks requiring an appreciation of the structure of transformed sentences
is some function of the nature, number and complexity of the grammatical
transformations involved."
(Miller \& Chomsky 1963, 481)

The form-centered approach starting from these ideas was the first step in modern psycholinguistics. Starting with studies by George Miller (1962) and his group, the experimental psycholinguistic research program took off. While it had its own development over half a century, it also moved psycholinguistics to a central place in modern psychology (Miller 1990).

Miller (1962, for a late summary, see Miller 1990) initiated the actual implementation of these ideas into research on the role of grammar in speech comprehension. His students like Susan Carey, Roger Shepard, Donald Norman, and most importantly, psycholinguists like Tom Bever and Jacques Mehle were to become central in cognitive research. These first-generation cognitive students would become the new mainstream generation of cognitive psychologists and sentence processing psycholinguists. Within psycholinguistics proper, regarding the centrality of syntax, the primacy of form over meaning, and rules over reshaped habits in the behaviorist sense resulted in several debates during the last half century. In sentence understanding for example, meaning-centered approaches soon emerged. Some of them also started to question the assumed temporal primacy of form-based processes (Sachs 1967; Johnson-Laird \& Stevenson 1970; Fillenbaum 1973; Flores d'Arcais 1974). In a famous series of studies using lexical access during sentence processing, parallel form- and meaning-based models have been proposed:

"The results demonstrate that both types of analysis [formal and semantic] are actively engaged in processing the input from the first word of a sentence onwards, and that there is no sign of any delay relative to the syntactic analysis of the input. Thus, there is no evidence that the global structure of sentence processing is ordered in time in the ways which the autonomy assumption requires."

(Marslen-Wilson \& Tyler 1980, 57) 
Similar effects started to be much discussed, because they were not merely interpreted as signs of the speed of understanding, but also as signs of constant interaction between multiple information sources, especially language-related and more general knowledge-related sorts of information during sentence processing. The group of scholars who belonged to the "interactionist camp", such as the connectionists, claimed that we are fast because all of our mind is transparent and uses all information in a parallel manner, while the form-centered people claimed that in these situations the context does not change word recognition, it merely softens the acceptance criteria. As summarized by the textbook of Clark and Clark (1977) early on, form-based, content and knowledge-based, and interactionist models soon started to develop (for a classic example of the interaction issue see Forster \& Olbrei 1973). The essential point for the Chomsky inspiration here is not the relative truth of these models. For all of them the starting point was the strictly formal approach emulating Chomsky.

The same is true for the recurring debates between rule-based and habit-based models of representation and processing over half a century, as summarized in Table 1.

Chomsky and his followers criticized learning theory principles in and via language acquisition. Language acquisition was characterized by them as a self-organization and rule formation, and the unfolding of innate programs rather than association and environmental determination (Chomsky 1959; Miller \& Chomsky 1963). This was the beginning of a straightforward dual view of mental functioning: there is a mechanistic and a structuredependent mode of functioning. For complex forms of behavior such as language, structure-dependent rule following is the norm. From the late sixties on, however, this view of dual organization was gradually replaced by an overarching unifying trend within the same structure and form centered group. Specifically, a conception took shape suggesting that all interesting processes should be dealt with in the framework of structure-dependent processes and hypothesis testing rather than association. This was accompanied by an explicit denial of the role of habit formation in establishing language competencies. This conception replaced the duality of learning versus rules, association versus structure with an overwhelming structuralism (Chomsky 1968). Here again, the starting point for the compromise models were the rule-based models stating from Chomsky.

The debates on rules concentrated specifically on language where the testing ground was the system of the English past tense. The starting point is that children at certain ages do overgeneralize the general rule of -ed past tense to irregular or so-called strong verbs. They say goed rather than 
went, comed rather then came. Traditional cognitive accounts claimed that overgeneralization errors observed in children around 3-4 years indicate the emergence of rules compared to earlier reliance on elements. In research traditions, this was followed by a victory of rules across the board. The new approach introduced by generative grammar concentrated on rules in understanding and the learning of language as opposed to simple patterns and habits.

Rumelhart and McClelland (1986) in an associative countermove with their connectionist model proposed that one does not need to postulate rules at all here. A proper statistical learning machine can produce the same errors as children make. Rumelhart and McClelland treated rules not as internal inherent laws of the mental system but as external characterizations of the products of the mental system. They were running computer programs that were reproducing the error pattern of children with simple associative item learning, eliminating the level of rules from the proposed mechanism.

From the history of ideas point of view, it is interesting that after the great controversies of symbol processing versus sub-symbolic i.e., connectionist networks (Rumelhart \& McClelland 1986; Clark 1989), synthetic works by Pinker $(1991 ; 1999)$ in the following decade allowed symbolic and rule-based systems for syntax and regular morphology (learn-learned), and an associative item-based (connectionist) network for irregularities (teach-taught) and for words in general. Pinker proposed a dual model, where the duality represented smart, rule-based systems along with probability-based associative subsystems. The rule systems would be related to the anterior, frontal parts of the cortex, while the item-based associative system to the posterior, temporal part in line with clinical and brain research data. Still later models such as Ullman's (2001) tend to juxtapose the two systems in a new manner as a procedural system (rules) versus a declarative system (words). In this way, the entire symbolic-sub-symbolic debate of grammar versus connections has become an issue of how to put cognition into the explicit/implicit dimension or into Gilbert Ryle's (1949) differentiation between KNOWING WHAT and KNOWING HOW. Classical information processing machines and the corresponding psychology would be criticized for singling out the world of KNOWING WHAT while the domain of KNOWING HOW, i.e., the domain of skills would become critically important.

Psycholinguistics has developed into a rich leading field in the cognitive domain. A volume for psycholinguistics in the new Millennium edited by Anne Cutler (2005) pointed out the many-faceted nature of recent psy- 
Table 1: The fate of rules over half a century of cognitive research

\begin{tabular}{lll}
\hline Stage features & Main topic about rules & Representatives \\
\hline $\begin{array}{l}\text { Rules win over habits 1960- } \\
1970\end{array}$ & $\begin{array}{l}\text { All higher behavior rule- } \\
\text { governed }\end{array}$ & $\begin{array}{l}\text { Generative grammar child: } \\
\text { Berko, Ervin, Slobin }\end{array}$ \\
\hline $\begin{array}{l}\text { Mental rules direct every- } \\
\text { thing 1965-1980 }\end{array}$ & $\begin{array}{l}\text { Linguistic rules have an in- } \\
\text { ner reality }\end{array}$ & $\begin{array}{l}\text { Miller, Bever, Mehler } \\
\text { Fodor, Slobin }\end{array}$ \\
\hline $\begin{array}{l}\text { Associative counter reac- } \\
\text { tions from } 1980 \text { on: connec- } \\
\text { tionism }\end{array}$ & $\begin{array}{ll}\text { Habits and frequencies in- } \\
\text { sules }\end{array}$ & $\begin{array}{l}\text { Rumelhart \& McClelland, } \\
\text { Bates \& MacWhinney }\end{array}$ \\
\hline $\begin{array}{l}\text { Dual models: Words and } \\
\text { Rules } 1990\end{array}$ & $\begin{array}{l}\text { Habits and rules for differ- } \\
\text { ent things }\end{array}$ & Pinker, Marcus, Ullmann \\
\hline $\begin{array}{l}\text { Dissociation of memories: } \\
\text { procedural/declarative } \\
\text { model }\end{array}$ & $\begin{array}{l}\text { Rules belong to the proce- } \\
\text { dural knowledge system }\end{array}$ & Ullmann \\
\hline
\end{tabular}

cholinguistics. The four key moments according to her are linguistics, biology, experimental study of production and comprehension, and the relations between modeling and experimentation. During its half a century career several lines of explanatory models developed in psycholinguistics. In the explanatory models pro or contra, the Chomsky inspiration is clearly present.

A. Internalist linguistic-psychological explanation. The understanding of computations is an explanation in itself. Difficulties of sentence processing might be explained by the allocation of working memory resources, for example. This corresponds to the original mentalistic and formal inspiration of Chomsky.

B. Neural. Especially due to evoked potential technologies becoming easier to handle and more sensitive, and due to the appearance of functional brain imaging while processing language, computational explanations started to look for different brain localizations and temporal components of supposed sub-processes such as early syntax, later syntax, semantics, and pragmatics. The Chomsky inspiration emerges in the temporal primacy of formal processing proposals (Friederici 2002). 
C. Computational models. Strong claims have been proposed both in processing and in development by postulating powerful general pattern-generating statistical procedures. A theoretical and, at the same time, empirical debate emerged between statistical and grammar-like computations. Regarding processing, the statistical approach is a radical interactionist move, and regarding development it corresponds to general (statistical) learning mechanisms as contrasted to grammar-specific models (see Gervain 2014 for the debates). But in a way again, in its theoretical motivation it goes back to, and challenges, the early fights of Chomsky (1956) against statistical models of language.

D. Evolutionary. Distal (final) explanations are sought for even in psycholinguistics, in general, or specifically in human evolutionary explanations, such as human sociality and its role in structuring even sentences. The "usage based" pragmatic theory is supposed to find its evolutionary anchorage (Tomasello 2003). This, again, is a strong reaction against the exaptation-based structural self-sufficient models proposed by Chomsky $(2005 ; 2015)$, though there are several compromise proposals like that of Jackendoff (1992).

E. Social. Both processing and development should be interpreted in basically pragmatic frames. These frames, on the other hand, are grounded in the behavioral and communicative coherence or in the socialization practices, related to intention attribution and naïve pedagogy (Csibra \& Gergely 2007; 2009).

The formal models entertained by early psycholinguistics had broader implications as well. Formal models extended to the study of many other fields of cognition. Structural trees analyzing the contexts in episodic memory appeared in the study of memory. Rewriting rules and corresponding sentence like trees appeared, which treated actual events in a sentence structure-like manner like I STUDY IN THE LAB [John kissed Mary] (Anderson $\&$ Bower 1973). The formal approach even appeared in the study of story organization, where rewriting rules and tree structures of the kind STORY $\rightarrow$ Setting + Episode, Episode $\rightarrow$ State + Attempt, Attempt $\rightarrow$ PlAN + ACTION + OUtCOME were proposed. The resulting structures had a neat similarity to the sentence structures of Chomsky (1965), on which they were explicitly relying. The inspirations from Chomsky were more language based compared to the mere use of graphs in decision theory. Following Rumelhart (1975) "Several models of story grammars were 
proposed. Essentially, all of them treated stories as a series of embedded attempts trying to achieve a Goal" (Pléh 2003, 192). Later on, these grammar- and form-based models were replaced by more social interpretation and attribution based models, but the important starting point was the analysis of pure form (for a survey of a generation of research on story grammars, see Pléh 2018).

Regarding the models of form-based representations, the aspect of time has become a central dimension. On the basis of relating decision times and stimulus differences, levels of representation were suggested that were themselves ordered in time, claiming by an extension of the attitude about the primacy of formal syntax, a form-based computation and a formcentered representation as the first level. A form $\rightarrow$ meaning sequence was postulated everywhere, from letter recognition to story paraphrases. The models were treating humans in information processing terms (Broadbent 1958; Lachman et al. 1979). It has soon become evident that the temporal fate of different codes and representations is a flexible process. The context and the task have been shown to have a determining influence over the retention of different codes.

\section{The centrality of sequential thought}

There were classical ideas regarding the psychology of language two generations before Chomsky that emphasized that syntax and sentential organization were crucial because in sentences there was an assumed transition from a holistic organization of thought towards a sequential unfolding in speech. Wilhelm Wundt was claimed to have summarized these classical ideas in the analysis of simultaneous-successive transitions as the essence of sentence structure (Bever 1970). Wundt was rediscovered by classical cognitive psychology. Blumenthal (1970) went as far as to claim Wundt to be a precursor of the notion of deep and surface structure as proposed by Chomsky (1965).

These antecedents for the new grammar were rediscovered as distant ancestors by Bever and Blumenthal. A crucial, broader and not merely historically interesting role was played by the theoretical and experimental neobehaviorist Karl Lashley in his proposal for sequential organization as an argument for all kinds of internal organization. Lashley (1951) claimed that even to explain co-articulation effects or speech errors one has to postulate neural representations of linguistic units rather than mere reflex chains. Sequential behavior is moving too fast and is too finely tuned to the context to be merely regulated by chain reflexes and feedback loops. 
Chain reflexes could not account for anticipatory errors, for the fact that something coming later has an influence on behavior. One has to postulate internal plans and their execution cycle to account for sequentially organized fast behavior:

"Finger strokes of a musician may reach sixteen per second in passages which call for a definite and changing order of successive finger movements. The succession of movements is too quick even for visual reaction time. [...] Sensory control of movement seems to be ruled out in such acts. They require the postulation of some central nervous mechanism which fires with predetermined intensity and duration or activates different muscles in predetermined order." (ibid., 123)

From these general considerations of movement organization, Lashley moved on to grammar:

"Any theory of grammatical form which ascribes it to direct associative linkage of the words of the sentence overlooks the essential structure of speech. The individual items of the temporal series do not in themselves have a temporal 'valence' in their associative connections with other elements. The order is imposed by some other agent."

(ibid., 116)

The issue of syntax is relevant for all complex movements, thus, linguistic organization, as shall be the case promoted by Chomsky, is a model for all complex organizations.

The sequential internal organization idea promoted by Lashley has come up in modern cognitive psychology in two lines of arguments. Chomsky $(1959,48)$ in his most influential review of Skinner's book on Verbal behavior commented several places on the Lashley paper, claiming in the long run that it argues for a grammatical analysis:

\footnotetext{
"In short, it should be possible to derive from a properly formulated grammar a statement of the integrative processes and generalized patterns imposed on the specific acts that constitute an utterance. [...] The problem of specifying these integrative processes and selective mechanisms is nontrivial and not beyond the range of possible investigation. The results of such a study might, as Lashley suggests, be of independent interest for psychology and neurology (and conversely)."
}

Even in the third edition of his seminal Language and mind book in 2006 Chomsky complained how unnoticed the Lashley paper was:

"Critical voices, even those that commanded considerable prestige, were simply unheard. For example, Karl Lashley gave a brilliant critique of the prevailing framework of ideas in 1948, arguing that underlying language use - and all organized behavior - there must be abstract mechanisms of some sort that are not analyzable in terms of association and that could not have been developed 
by any such simple means. But his arguments and proposals, though sound and perceptive, had absolutely no effect on the development of the field and went by unnoticed even at his own university (Harvard), then the leading center of psycholinguistic research. Ten years later Lashley's contribution began to be appreciated, but only after his insights had been independently achieved in another context."

Lashley's presentation at a high profile neuroscience symposium, the "Hixon symposium", had a large effect. The audience was filled with people like John von Neumann, Lorente de Nó, McCulloch and so on, leading neuroscientists arguing for internal neural organization and cognitive model makers. As a matter of fact, due to the attention of the high-prestige audience and to the analysis of Chomsky, Lashley did not remain unnoticed.

Most interestingly, the other neobehaviorist whom Chomsky saved from his own critique of behaviorist models in the 1960s was Edward Tolman (1932) with his assumed plans underlying animal behavior. The interesting point is that while the sequential internal motor patterns emphasized by Lashley corresponded to the issue of sequentialization in complex behaviors, Tolman (1948) with his internal maps argued for a holistic vision of internal mental life. Tolman was a great name in his time, and his debates with the followers of Hull on place versus response learning in mazes were central to theories of learning. This seemingly outdated debate is still relevant. For the cognitivists it is related to the issue of whether we are entitled to postulate animal representation systems. The cognitive approach to learning represented by Tolman became popular in psychology from the 1970s. Cognitive maps in cognitive psychology are no longer outlandish extravagant notions, but trivialities. Chomsky (1968) in his Berkeley talks presented Tolman as a forerunner of his own mentalistic modelling.

It is rather intriguing for the history of ideas that in much later works of his Chomsky (2015) has himself gone back to the issue of simultaneoussequential organization. He basically claims now that the plans in the Internal I-language are non-sequential in nature, and sequentiality is enforced by turning to the phonetic-acoustic interface. Thus, in a way, the original issue of Wundt and Lashley of how to put holistic thought into articulated sequential output comes back.

The issue of sequentiality has become widespread beyond Chomsky's own work by the book of his close early associate George Miller. The famous planning conception proposed by Miller et al. (1960) saw in sentences the basic form of a structure-based holistic planning rather than "mere prediction". The theoretical book argued for the postulation of pre-existing plans of behavior, starting from simple movements to complex plans of chess or language. 


\section{A computational theory of mind}

The hierarchy of languages proposed by Chomsky (1956) had a central role in the unfolding of modern computational linguistics. The attitude of Chomsky is in several ways ambiguous in this regard. He follows the humanist tradition of modern linguistics by claiming the specificity of human language, and at the same time, he is convinced that linguistics is a natural science. He is the founding father of modern computational linguistics, but at the same time he is not too sympathetic to computer-inspired reductionism in the study of human cognition. As a result of these ambiguities, he has become an inspiration of computational theories of the human mind on two levels: on a concrete level of a syntactic theory of mind, and on a more abstract level, as one of the proponents, along David Marr, of a more subtract multilayered computational approach to the mind.

On the first level, Chomsky and his vision of language played a central role in the birth of a syntactic theory of mind (Fodor 1981; 1985). As Forgács (2010) in his review of Fodor (2008) emphasized, while Chomsky mostly remained neutral regarding the extensions of his theory to the integrity of human thought, Fodor (1975) became the first lord of an extended syntactic theory of mind. The language of thought (LOT) hypothesis promoted by Fodor (1975) rephrased the Leibnizian topic in the light of the machine age. Programming languages translate instructions of a higher order into instructions of a lower order, to arrive at a machine code at the end. Similarly in humans: there is a final language, a mentalese. Human thought can be interpreted as an organization, where some final instances (the very propositional organization) correspond to a pre-wired language. The proposal that the language of thought is similar to a machine code is intended to avoid an infinite regress. "While all thought is symbol manipulation, i.e., translation, finally there is a language, a form of thought provided by nature herself. The LOT is a linguistic a priori system" (Pléh 2008, 218). Hinzen (2017) has a similar claim about not merely postulating a propositional syntax for thoughts, but basically identifying it with linguistic syntax. ${ }^{1}$

But even psychologists of the first cognitivist generation who have in many empirical regards become meaning-centered, like Jerome Bruner (1983) also treated the "structuralism" of the cognitive efforts as central. This was mostly accompanied by a decompositionist vision, which is also familiar from the arts: dissecting complex processes into simple compo-

${ }^{1}$ I would like to thank Csaba Czeglédi for reminding me of the importance of Hinzen in this regard. 
nents. In the syntactic theory of mind representational relations are principally of a linguistic nature, and meaning and representation is a secondary step in any processing. Human thinking is interpreted as a merely formal system. In a syntactic engine, sentences lead to other sentences and in our mind propositions lead to other propositions (Clark 1989). Ideas themselves would be organized in a sentence-like manner (Fodor 1975). The postulated Language of Thought in this Syntactic Theory of Mind is responsible for a comprehensive internal mental organization, with implicational relations between representations.

On the more abstract level of computational theory, the inspiration of Chomsky was parallel to the ideas of David Marr, who proposed the idea of formal analysis, and the structure of research even into the study of vision. According to Marr (1982), the first task of the scientist is to make a conceptual analysis into the problem, which is the "computational level" in the logics of research. There is a one-to-many relationship between this level and that of the algorithms actually used by humans, which is the second level. The third level would be the actual software-based or neural implementation of the algorithm. In principle, several realizations could be made available for the very same computational theory. That is the reason why the work of Marr has become an influential model in cognitive science. This is a new pattern different from the one proposed by early artificial intelligence researchers. For the early studies the starting point was the program rather than the structure of the cognitive task. The thesis of Marr was a thought provoking realization of the possibility of machines on an abstract level.

In a similar manner, Miller and Chomsky (1963) emphasized half a century ago in connection with language that the theories of performance (e.g., speaking, the third, implementation level in Marr's terminology) have to embody a grammar, a theory of competence, and a naïve model of language that is necessary for the acquisition of the language by each native user. Or to put it in another way, it needs a theory about the requirements that any implementation theory has to fulfill. In a way, the Chomskyan (1965) distinction between competence and performance corresponds to the computational and algorithmic levels assumed by Marr (Gentner 2010). And the third level, the implementation level would correspond in language to what Tom Bever (1970) a long time ago claimed to be the issue of performance mechanisms. 


\section{Generic innatism and specific innatism}

Some of modern linguistics together with accompanying psycholinguistics openly advocated a Cartesian cognitive message (Chomsky 1966; 1986). For Chomsky innatism was one way to overcome the "empty organism" and "black box" metaphor of the behaviorists. Innate organizing principles of language and other complex human achievements belong to "speciesspecific behaviors" in the style of the early ethologists. In the hand of his followers, this general innatism claim has usually been transformed into the specific innatism claims of the modularists (Fodor 1983).

\section{Two types of genetic reasoning in modern psychology}

In the late 1950s there were two roads within psychology that led to an interest towards the genetic determinants of behavior. The first one was the idea of universal nativism, the second the issue of the genetic determinants of individual differences, as summarized in Table 2.

Table 2: New biological ideas about the determination of development in the 1960s

\begin{tabular}{llll}
\hline Type of innovation & Key novelty & Opponents & Leading representatives \\
\hline Universal nativism & $\begin{array}{l}\text { Cognitive structures } \\
\text { are } \text { a priori }\end{array}$ & Learning theories & Chomsky, Fodor \\
\hline $\begin{array}{l}\text { Inheritance } \\
\text { of differences }\end{array}$ & $\begin{array}{l}\text { Individual differences } \\
\text { are innate }\end{array}$ & $\begin{array}{l}\text { Differences based } \\
\text { on nurture }\end{array}$ & $\begin{array}{l}\text { Hans Eysenck, } \\
\text { Arthur Jensen }\end{array}$ \\
\hline
\end{tabular}

The psychological interests were in a way continuously divided. Some people were and are mainly interested in the genetic components of individual differences, while others in the generic, species-specific, supposedly innate determination of certain functions. In a comprehensive biological theory, these two issues are certainly not separated. In the Darwinian model, variations are all over the place, and the extended Darwinian model, the "modern synthesis" from the 1930s on, connected the idea of variation to genetics in a population-statistical manner. Interestingly, however, in psychology, the two interests continued to develop separately for quite a time, well into the second half of the 20th century. It is a rather peculiar merit of Chomsky that his approach and stance on innatism had a say in both regards. 


\section{Generic inheritance}

The work of the "generic innatist" group followed the argumentation initiated by Chomsky, and applied it to psychology in a universalistic manner. Most of the research was interested in the early development of some particular abilities, or domains as they preferred to call them later on, like language, numbers, face recognition, and the like. The main arguments for a generic genetic determination were based on early developmental manifestations, cross-species comparisons, content-specific developmental disorders, and less frequently, real cross-cultural comparisons.

Chomsky thought that the arguments for an innate system underlying language were: its universal structural features, contrasting it with animal communication systems; and most importantly, for the psychologists, its universal and fast acquisition, based on limited and distorted data, and its following a critical-period style of development. The critical period theories, which represented for Chomsky the classic ideas of German embryology in the work of his teacher, Eric Lenneberg (1967), were an accommodation of the innatist theories. Before the formation of recent epigenetic theories of development, they were allowing for the influence of individual experience factors supplementing the innate mechanism, usually talking about species-specific stable environmental factors in the sense of Donald Hebb (1949). It is of historical interest that Chomsky has taken these ideas from his European mentors. He identified his distant inspirations (Chomsky 1966) from Descartes and Port Royal grammar to Humboldt. But he had more local inspirations as well. A most likely key influence was Roman Jakobson who was teaching at Harvard at the time Chomsky was there. Jakobson claimed as early as 1941 that there are universal tendencies across languages in the acquisition of the sound system, and the system unfolds in a preprogrammed universal manner. Another European refugee, Eric Lenneberg (1967), was transmitting all the mid-20th century German biological and innatist ideas, together with an inspiration to read modern ethology. As he mentioned at several places (Chomsky 1965, 1968), the new discoveries of neuroscience about geometrically sensitive cortical structures (Hubel \& Wiesel 1959) and the idea of Lorenz (1941/1962) were important immediate motivations for his innatism.

Regarding the mechanisms of language acquisition the original rather strong, but rather philosophical claims of the Chomskyan generic innatist stance have been taken seriously by the data-minded cognitive researchers as well. Debates developed over two generations, but the starting point for the debate was the strong innatist claim. The original Chomskyan 
philosophical claims about innatism were turned into empirical claims by merciless psychologists. Chomsky himself became ambivalent regarding the interpretation of these scientific developments initiated by him. Recently, he moved back to a position overstepping the identification of innatism with genetic determination. According to Chomsky (2005; Chomsky \& McGilvray 2012), innatism is assumed to follow from universal constraints due to the physical organization of the world in a physicalist naturalistic theory, rather than from genetics.

Table 3 shows the changes in the conception of Chomsky himself, partly as a consequence of the changes brought about by empirical psychological studies between 1967 and 2012.

Table 3: The early and later innatism and biolinguistics arguments of Chomsky

\begin{tabular}{lll}
\hline Aspect & Early 1960s & 2000s \\
\hline Rationalism & Innate system & Innate system \\
\hline Development & Abduction acquisition & Parameter setting \\
\hline Mental structure & Modular mental organ & Genetic modularity \\
\hline Inner buildup & Syntax is central & I-language, UG, recursion \\
\hline Biology of origin & Macro mutation and exaptation & Tinkering, universal physics \\
\hline
\end{tabular}

The concept of innatism under the inspiration of the generative grammar initiated by Chomsky was dynamically changing during the last half century, both within the innatist group and in creating new oppositions to it. Chomsky originally used a conceptual epistemological reasoning in favor of innatism. He pointed out, without too much evidence being available in the 1950s, that on the basis of accidental experience all children develop a grammar showing universal features, and each child roughly follows an identical pathway. Furthermore, this happens with little instruction and little feedback from the environment (the "poverty of stimulus" and "no negative evidence" principles). The theoretical innatism of Chomsky has led to empirical translations in the language sciences. The most essential thing has become modern child language research, using observational and experimental methods. This has partly followed the Chomsky inspiration (Brown 1973), but some of its representatives have questioned the innatist program in many ways, particularly regarding the setting of parameters during development. In the 1970s Jerome Bruner (1974) did so 
on the basis of a social theory of development, and in the 1990s Annette Karmiloff-Smith (1992) and Elman et al. (1996) proposed a combination of actual developmental patterns with a reinterpretation of modularity and innatism. Recently Michael Tomasello (2003) and Gergely Csibra and György Gergely (2009) have argued for the formative role of the environment in the unfolding of the linguistic system in children. The poverty of stimulus conception promoted by Chomsky is replaced by a modern, ethologically inspired argumentation where the child and the environment form a combined learning-teaching system together. It is the very process of acquisition which is assumed to be innately organized, not the grammar itself. But here again, the very provocative strong initial claims by Chomsky (1967) have become a motivation for half a century of actual research controversies.

The same is more or less valid for the implications of the biolinguistics program for the origin of language issue. Chomsky (1967) started from strong claims regarding the sudden appearance of human language, its unique organization compared to animal communication systems which are restrained, use motivated signs and so on. Half a century of ethological work has been motivated by trying to disprove these claims, showing the gradual development of signing systems, their stepwise complication and the likes. Chomsky even when he accepted these new developments with regard to gradual developments he maintained that this is merely Faculty of Language Broadly taken, and Faculty of Language in the Narrow sense is still unique, comprising the suddenly appearing recursive syntax (Hauser et al. 2002). The human-specific proposals of the humanist were motivating decades of research of the naturalists.

\section{The views of Chomsky on the inheritance of intelligence}

At roughly the same time when the modern innatist program in cognitive research was born with the initiation of Chomsky (1967), the issue of genetic determinism of human behavioral and intellectual individual differences became the focus of increasing scientific attention again. This reemerging view also started in the mainstream as a criticism of behaviorism. The new psychogeneticians denied that the behaviorists' simple life history based empiricism could be a possible way to explain individual differences. To explain individual differences, they referred to the Galtonian paradigm that proposed heredity to be crucial in determining individual differences in behavior, and basically presupposed an additive role of nature (genetics) and nurture (environment) (for a critical contempo- 
rary stance on this, see McLafferty 2006). The followers of Galton considered even interaction as a mere statistical term, and did not consider the possibilities of substantial proactive visions of interaction, where human agents as environmental factors factually enter the causal chain, in changing schooling patterns, for example. In the individual variation domain, the interest in the genetics of intelligence was often linked to a conservative social philosophy and to a belief in a stable social order. It remained true for the late 20th century as well (Burt 1961).

There was a wider context to all of these debates that was raised at the time by Chomsky (1978). Chomsky as a representative of both the generic innatist group and a radical left-wing social thinker questioned several issues in the reasoning of one of the most open advocates of the genetics of intelligence vision, the position of Jensen (1969), and especially that of Herrnstein (1973) in a rather radical manner, as well as some of the naïve liberal criticisms directed against Herrnstein. First, Chomsky expressed his puzzlement why the possible inheritance of any trait is such a disturbing social issue:

"The question of heritability of I.Q. might conceivably have some social impor-
tance, say, with regard to educational practice. [...] It is, incidentally, surprising
to me that so many commentators should find it disturbing that I.Q. might be
heritable, perhaps largely so. Would it also be disturbing to discover that rel-
ative height, or musical talent, or rank in running the 100 yard dash, is in
part genetically determined? Why should one have preconceptions one way or
another about these questions?"
(Chomsky 1972b, 44)

He moved on to more basic and disturbing social issues, to question the very distribution of social rewards:

"It is alleged that in our society remuneration correlates in part with IQ. But insofar as that is true, it is simply a social malady to be overcome much as slavery had to be eliminated at an earlier stage of human history. [...] The standard arguments for 'meritocracy' have no basis in fact or logic." (Chomsky 1978, 122)

Only capitalist society distributes rewards in a meritocratic manner:

"Consider [...] the claim that IQ is a factor in attaining reward and that this must be so for society to function effectively. Herrnstein recognizes that his argument will collapse if, indeed, society can be organized in accordance with the 'socialist dictum', 'From each according to his ability, to each according to his needs'. His argument would not apply in a society in which 'income (economic, social, and political) is unaffected by success' [according to Herrnstein], transmittable wealth and power accrue to mental ability, and must, for society to function effectively. If this assumption is false and society can be organized more or less in accordance with the 'socialist dictum', then nothing is left of Herrnstein's argument."

(Chomsky 1972b, 34) 
According to Chomsky, another misleading factor is related to the very notion of intelligence. Differences in intelligence between groups are measuring the wrong thing:

"We have to study less complex issues. An inquiry into such questions as race and
IQ appears to be of virtually no scientific interest. Conceivably, there might be
interest in correlations between partially heritable traits, but if someone were
interested in this question he would surely not select such characteristics as race
and IQ, each an obscure amalgam of complex properties. Rather, he would ask
whether there is a correlation between measurable and significant traits, say,
eye color and length of the big toe. It is difficult to see how the study of race
and IQ can be justified on any scientific ground." (Chomsky 1978, 132)

Chomsky arrived at the same conclusion as Pinker (2002) a generation later: social equality of opportunity is not an issue of abilities, but an issue of principle:

"Human talents vary considerably, within a fixed framework that is characteristic of the species and that permits ample scope for creative work, including the creative work of appreciating the achievements of others. This should be a matter for delight rather than a condition to be abhorred. Those who assume otherwise must be adopting the tacit premise that a person's rights or social reward are somehow contingent on his abilities. [...] In a decent society opportunities should confirm as far as possible to personal needs, and such needs may be specialized and related to particular talents and capacities."

(Chomsky 1978, 127)

Pinker continues with similar claims. The claim of universal human nature should be accompanied by accepting the large individual differences at the same time. According to Pinker, the difficult task is to accept differences and at the same time believe in equality. We should stand for equality on a moral basis. At the same time, with all the genetic variations acknowledged, we should see clearly that these variations are relatively small, compared to other primates.

\section{Human freedom and the freedom entailed in human language}

Chomsky's influence as an anarchist political thinker (Chomsky 1972a;b; 1986; 1988) and as a constant critic of American politics, of the distortive strategies of the media, and of international anti-liberal trends also made him a rather central visionary of the image of man in modern psychology. His views on language and on freedom are intrinsically related. Chomsky is a leading proponent of a theory where humans are unboundedly free and this freedom is related to the central, distinct, human-specific feature, 
namely the design of human language which is characterized by unbounded creativity.

Language, while it is genetically determined, is not a constraint on thought. Rather, by its very structure, due to its openness, language, both as a system and in its actual use, is unbounded and unlimited, and therefore it also ensures the unlimited free development of humanity (Chomsky 1972a; 1978; 1988). In the tradition of relating freedom and epistemology, in European modern development empiricists tended to be freedom-oriented, like John Stuart Mill, and rationalists tended to be more authority-oriented. Chomsky has broken this alliance. He preaches an innatist vision of the human mind that entails undeniable freedoms. Human cognition is characterized by certain prepackaged cognitive systems, which constitute part of our human nature (Chomsky 1967; 2015).

This break with the tradition of liberalism $=$ environmentalism was summarized by Steven Pinker (2002). Pinker in his book criticizing the environmentalist position exposed this universalistic innatist attitude clearly as a positive program. He showed that for many people the Darwinian commitment to an image of human nature was usually accompanied by a rather liberal egalitarian social philosophy. According to Pinker, and the entire universalist-innatist group, the traditional combination of egalitarian commitments with enviromentalist psychological positions was a mistaken path. The starting point for the optimists should be, on the one hand, a postulation of a rich human nature, and acceptance of the very rich human universals.

Human language is central to this system, due to its inherent creativity. Technically, this creativity is related to his views on recursion, which show up in all stages of his work (Chomsky 1957; 2005; Hauser et al. 2002). When Chomsky started these claims, his approach to the creativity of language fit into the general new enthusiasm of psychology about creativity. However, his approach was different in a crucial regard from the cultivation of creativity in the psychology of the 1960s. The psychological approaches were mostly unstructured, loose associative conceptions of the creative nature of the human mind, while Chomsky (1957) concentrated on creativity as being structure-sensitive and rule-based. The creativity of syntax is based on a rule system, as I tried to show at the time (Pléh 1976). Formal syntactic creativity remained a central point of the Chomskyan vision of creativity, even when it became supplemented by semantic and theory of mind based pragmatic creativity (Kenesei 2013). The unbounded and unconstrained creativity of language is a crucial assurance for human freedom. It insures that our expressive system is not an obstacle to thought. 
In this refreshed rationalistic vision the frames of thought do not come from experience. This sort of innate determination, however, is a key to the uniformity and universality of the human condition. Were our thinking entirely at the mercy of the environment, we would be entirely victims of the accidental features of the environment, thus we would not be free. In fact, the secret of freedom is that our thought has experience-independent features.

\section{Acknowledgments}

This paper is based on several talks I have presented on the impact of Chomsky in psychology and the cognitive sciences, on the occasion of his 80th and 90th birthdays, and two papers on these occasions (Pléh 2009; 2019). I am grateful for the invitations for these occasions and several comments from István Kenesei, and comments from Csaba Kecskeméti, Bálint Forgács, István Fekete and Judit Gervain, as well as the close reading and advice from Éva Dékány. The paper owes much to a broader treatment of the history of the cognitive movement I had the privilege to work on at the Collegium de Lyon in 2015/2016. That is the reason for the dual affiliation.

\section{References}

Anderson, John R. and Gordon H. Bower. 1973. Human associative memory. Washington, DC: V. H. Winston \& Sons.

Baars, Bernard J. 1986. The cognitive revolution in psychology. New York: Guilford Press.

Bever, Tom G. 1970. The cognitive basis for linguistic structures. In R. Hayes (ed.) Cognition and language development. New York: Wiley. 279-362.

Blumenthal, Arthur. 1970. Psychology and language: A historical introduction to psycholinguistics. New York: Wiley.

Broadbent, Donald E. 1958. Perception and communication. London: Pergamon.

Brown, Roger. 1958. Words and things. New York: Free Press.

Brown, Roger. 1970. Psycholinguistics: Selected papers. New York: Free Press.

Brown, Roger. 1973. A first language: The early stages. Cambridge, MA: Harvard University Press.

Bruner, Jerome S. 1974. From communication to language. A psychological perspective. Cognition 3. 225-287.

Bruner, Jerome S. 1983. In search of mind: Essays in autobiography. New York: Harper and Row.

Bruner, Jerome S. 1997. Will cognitive revolutions ever stop? In D. M. Johnson and C. E. Erneling (eds.) The future of the cognitive revolution. Oxford: Oxford University Press. 279-292.

Burt, Cyril. 1961. Intelligence and social mobility. British Journal of Statistical Psychology 14. 3-24. 
Carnap, Rudolf. 1934/1937. Logische Syntax der Sprache. English translation: The Logical Syntax of Language. New York: Harcourt.

Chomsky, Noam. 1956. Three models for the description of language. IRE Transactions on Information Theory 2. 113-124.

Chomsky, Noam. 1957. Syntactic structures. The Hague: Mouton.

Chomsky, Noam. 1959. A review of B. F. Skinner's Verbal behavior. Language 35. 26-58.

Chomsky, Noam. 1965. Aspects of the theory of syntax. Cambridge, MA: MIT Press.

Chomsky, Noam. 1966. Cartesian linguistics. New York: Harcourt.

Chomsky, Noam. 1967. Recent contributions to the theory of innate ideas. Synthese 17. $2-11$.

Chomsky, Noam. 1968. Language and mind. New York: Harcourt, Brace \& World.

Chomsky, Noam. 1972a. Problems of knowledge and freedom: The Russell lectures. New York: Vintage Books.

Chomsky, Noam. 1972b. Psychology and ideology. Cognition 1. 11-46.

Chomsky, Noam. 1978. Language development, human intelligence, and social organization. In W. Feinberg (ed.) Equality and social policy. Champaing, IL: University of Illinois Press. 120-143.

Chomsky, Noam. 1980. Rules and representations. New York: Columbia University Press.

Chomsky, Noam. 1986. Knowledge of language: Its nature, origin and use. New York: Praeger.

Chomsky, Noam. 1988. Language and problems of knowledge: The Nicaraguan lectures. Cambridge, MA: MIT Press.

Chomsky, Noam. 2005. Three factors in language design. Linguistic Inquiry 36. 1-22.

Chomsky, Noam. 2015. What kind of creatures are we? New York: Columbia University Press.

Chomsky, Noam and John McGilvray. 2012. The science of language: Interviews with Noam Chomsky. Cambridge: Cambridge University Press.

Clark, Andy. 1989. Microcognitio. Cambridge, MA: Bradford Books/MIT Press.

Clark, Eve V. and Herbert H. Clark. 1977. Psychology and language: An introduction to psycholinguistics. New York: Harcourt Brace Jovanovich.

Cohen, David. 2004. Psychologists on psychology. London: Hodder and Stroughton.

Cohen-Cole, John. 2005. The reflexivity of cognitive science: the scientist as model of human nature. History of the Human Sciences 18. 107-139.

Csibra, Gergely and György Gergely. 2007. 'Obsessed with goals': Fuctions and mechanism of teleological interpretation of actions in humans. Acta Psychologica 124. 60-78.

Csibra, Gergely and György Gergely. 2009. Natural pedagogy. Trends in Cognitive Sciences 13. $148-153$.

Cutler, Anne (ed.). 2005. Twenty-first century psycholinguistics: Four cornerstones. Mahwah, NJ: Lawrence Erlbaum.

Elman, Jeff, Elizabeth Bates, Mark Johnson, Annette Karmiloff-Smith, Domenico Parisi and Kim Plunkett. 1996. Rethinking innateness: A connectionist perspective on development. Cambridge, MA: MIT Press.

Fillenbaum, Samuel. 1973. Syntactic factors in memory? The Hague: Mouton. 
Flores d'Arcais, Giovanni B. 1974. Is there a memory for sentences? Acta Psychologica 38. $33-58$.

Fodor, Jerry A. 1975. The language of thought. Cambridge, MA: Harvard University Press.

Fodor, Jerry A. 1981. Representations. Cambridge, MA: MIT Press.

Fodor, Jerry A. 1983. The modularity of mind. An essay on faculty psychology. Cambridge, MA: MIT Press.

Fodor, Jerry A. 1985. Fodor's guide to mental representation: The intelligent auntie's vademecum. Mind 94. 76-100.

Fodor, Jerry A. 2008. LOT2: The language of thought revisited. Oxford: Clarendon.

Forgács, Bálint. 2010. Könyvismertetés [Book review]: Jerry A. Fodor: LOT 2: The Language of Thought Revisited, 2008. Magyar Pszichológiai Szemle 65. 555-563.

Forster, Kenneth I. and Ilmar Olbrei. 1973. Semantic heuristics and syntactic analysis. Cognition 2. 319-347.

Friederici, Angela D. 2002. Towards a neural basis of auditory sentence processing. Trends in Cognitive Sciences 6. 78-84.

Gardner, Howard. 1985. The mind's new science: A history of the cognitive revolution. New York: Basic Books.

Gentner, Daniel. 2010. Psychology in cognitive science: 1978-2038. Topics in Cognitive Science 2. 328-344.

Gervain, Judit. 2014. Developmental science and the nature-nurture issue: The case of language. In Cs. Pléh, G. Csibra and P. Richerson (eds.) Naturalistic approaches to culture. Budapest: Akadémiai Kiadó. 209-221.

Green, C. David. 1996. Where did the word "cognitive" come from anyway? Canadian Psychology 37. 31-39.

Green, Judith. 1973. Psycholinguistics: Chomsky and psychology. Harmondsworth: Penguin.

Greenwood, John D. 1999. Understanding the "cognitive revolution" in psychology. Journal of the History of the Behavioral Sciences 35. 1-22.

Hauser, Marc D., Noam Chomsky and W. Tecumseh Fitch. 2002. The faculty of language: What is it, who has it, and how did it evolve? Science 298. 1569-1579.

Hebb, D. O. 1949. The organization of behavior; a neuropsychological theory. New York: Wiley.

Herrnstein, Richard J. 1973. I.Q. in the meritocracy. Boston, MA: Little Brown.

Hilgard, Ernest R. 1980. The trilogy of mind: Cognition, affection, and conation. Journal of the History of the Behavioral Sciences 16. 107-114.

Hintikka, Jako. 1991. Overcoming "overcoming metaphysics through logical analysis of language" through logical analysis of language. Dialectica 45. 203-218.

Hinzen, Wolfram. 2017. Universal grammar and philosophy of mind. In A. Ledgeway and I. G. Roberts (eds.) Cambridge handbook of historical syntax. Cambridge: Cambridge University Press. 37-60.

Hubel, David H. and Thorton N. Wiesel. 1959. Receptive fields of single neurones in the cat's striate cortex. The Journal of Physiology 148. 574-591.

Jackendoff, Ray. 1992. Languages of the mind. Cambridge, MA: MIT Press. 
Jakobson, Roman. 1941. Kindersprache, Aphasie und allgemeine Lautgesetze. Uppsala: Almquist \& Wiksell. (In English: Child Language, Aphasia and Phonological Universals, The Hague: Mouton, 1968.)

Jensen, Arthur. 1969. How much can we boost IQ and scholastic achievement? Harvard Educational Review 39. 1-123.

Johnson-Laird, Philip N. and Rosemary Stevenson. 1970. Memory for syntax. Nature 227. 412.

Karmiloff-Smith, Annette. 1992. Beyond modularity: A developmental perspective on cognitive science. Cambridge, MA: MIT Press.

Katz, Jerrold J. 1964. Mentalism in linguistics. Language 40. 124-137.

Katz, Jerrold J. and Paul Postal. 1964. An integrated theory of linguistic descriptions. Cambridge, MA: MIT Press.

Kenesei, István. 2013. The role of creativity in the cognitive turn in linguistics. International Review of Pragmatics 5. 270-291.

Kuhn, Thomas. 1962. The structure of scientific revolutions. Chicago: University of Chicago Press.

Kuhn, Thomas. 1970. The structure of scientific revolutions (2nd, enl. ed.). Chicago: University of Chicago Press.

Lachman, Robert, James L. Lachman and Robert C. Butterfield. 1979. Cognitive psychology and information processing: An introduction. Hillsdale, NJ: Erlbaum.

Lashley, K. 1951. The problem of serial order in behavior. In L. A. Jeffres (ed.) Cerebral mechanisms in behavior. New York: Wiley. 112-131.

Lenneberg, Eric H. (ed.). 1967. Biological foundations of language. New York: Wiley.

Leslie, Allan M. 1987. Pretense and representation: Origins of a "theory of mind". Psychological Review 94. 412-426.

Lorenz, Konrad. 1941/1962. Kant's doctrine of the a priori in the light of contemporary biology. In L. von Bertalanffy and A. Rapoport (eds.) General systems: Yearbook of the Society for General Systems Research. Vol. VII. New York: Society for General Systems Research. 23-35.

Mandler, George. 2002a. Interesting times. An encounter with the 20th century. Mahwah, NJ: Erlbaum.

Mandler, George. 2002b. Origins of the cognitive revolution. Journal of the History of the Behavioral Sciences 38. 339-353.

Marr, David. 1982. Vision: A computational investigation into the human representation and processing of visual information. San Francisco: W. H. Freeman.

Marslen-Wilson, William D. and Lorainne Komisarjevsky Tyler. 1980. The temporal structure of spoken language understanding. Cognition 8. 1-71.

McLafferty, Claire L. 2006. Examining unproven assumptions of Galton's nature-nurture paradigm. American Psychologist 61. 177-178.

Mehler, Jacques. 1969. Psycholinguistique et grammaire générative. Langages 4. 1-13.

Miller, George A. 1962. Some psychological studies of grammar. American Psychologist 17. $748-762$.

Miller, George A. 1990. The place of language in a scientific psychology. Psychological Science 1. 7-14. 
Miller, George A. 2003. The cognitive revolution: A historical perspective. Trends in Cognitive Sciences 7. 141-144.

Miller, George A. and Noam Chomsky. 1963. Finitary models of language users. In R. D. Luce, R. R. Bush and E. Galanter (eds.) Handbook of mathematical psychology, vol. 2. New York: Wiley. 419-491.

Miller, George A., Eugene Galanter and Karl H. Pribram. 1960. Plans and the structure of behavior. New York: Holt.

Newell, Alan, Herbert A. Simon and James J. Shaw. 1958. Elements of a theory of problem solving. Psychological Review 65. 151-166.

O'Donohue, William, Karl E. Ferguson and Adam E. Naugle. 2003. The structure of the cognitive revolution: An examination from the philosophy of science. The Behavior Analyst 26. 85-110.

Olson, Gary A., Lester Faigley and Noam Chomsky. 1991. Language, politics, and composition. Journal of Advanced Composition 11. 1-35.

Palermo, David. 1971. Is a scientific revolution taking place in psychology? Science Studies 1. $135-155$.

Pinker, Steven. 1991. Rules of language. Science 253. 530-535.

Pinker, Steven. 1999. Words and rules. New York: Basic Books.

Pinker, Steven. 2002. The blank slate: The modern denial of human nature. New York: Penguin.

Pléh, Csaba. 1976. Ponjatie kreativnosti v psichologi i v sovremennom jazikoznanii. Annales Universitatis Budapestiensis Sectio Paedagogica et Psychologica 5. 90-95.

Pléh, Csaba. 2003. Narrativity in text construction and self construction. Neohelicon 30. 187-205.

Pléh, Csaba. 2008. History and theories of the mind. Budapest: Akadémiai Kiadó.

Pléh, Csaba. 2009. Chomsky és a pszichológia [Chomsky and psychology]. Magyar Tudomány 170. 1075-1081.

Pléh, Csaba. 2018. Narrative psychology as cultural psychology. In G. Jovanović, L. AllolioNäcke and C. Ratner (eds.) The challenges of cultural psychology: Historical legacies and future responsibilities. London: Routledge. 237-249.

Pléh, Csaba. 2019. Chomsky és a pszichológia: a nyelv mentális realitása és az egyéni különbségek [Chomsky and psychology: The mental reality of language and individual differences]. In I. Kenesei (ed.) Nyelv, biológia, szabadság. A 90 éves Chomsky jelentősége a tudományban és azon túl [Language, biology, freedom. The importance of the 90-year-old Chomsky in science and beyond]. Budapest: Gondolat. 55-83.

Pléh, Csaba and Lilia Gurova. 2013. Existing and would-be accounts of the history of cognitive science: An introduction. In Cs. Pléh, L. Gurova and R. László (eds.) New perspectives on the history of cognitive science. Budapest: Akadémiai Kiadó. 1-34.

Postal, Paul. 1964. Constituent structure: A study of contemporary models of syntactic description. The Hague: Mouton.

Quine, Willard van Orman. 1969. Ontological relativity and other essays. New York: Columbia University Press.

Rumelhart, David E. 1975. Notes on a schema for stories. In D. G. Bobrow and A. N. Collins (eds.) Representation and understanding. New York: Academic Press. 211-236. 
Rumelhart, David E., James L. McClelland and the PDP Research Group (eds.). 1986. Parallel distributed processing: Explorations in the microstructures of cognition. Vol. 1: Foundations. Cambridge, MA: MIT Press.

Ryle, Gilbert. 1949. The concept of mind. London: Hutchinson.

Sachs, Jacqueline Strunk. 1967. Recognition memory for syntactic and semantic aspects of connected discourse. Perception and Psychophysics 2. 437-442.

Skinner, Burhus F. 1963. Operant behavior. American Psychologist 18. 503-515.

Spelke, Elisabeth S. 2000. Core knowledge. American Psychologist 55. 1233-1243.

Tolman, Edward C. 1932. Purposive behavior in animals and me. New York: Century.

Tolman, Edward C. 1948. Cognitive maps in rats and men. Psychological Review 55. 189-208.

Tomasello, Michael. 2003. Constructing a language. A language based theory of language acquisition. Cambridge, MA: Harvard University Press.

Ullman, Michael Thomas. 2001. A neurocognitive perspective on language: The declarative/procedural model. Nature Review Neuroscience 2. 717-726.

Weimer, Walter B. and David S. Palermo. 1973. Paradigms and normal science in psychology. Social Studies of Science 3. 211-244. 